\title{
Organizational Voice Behaviour and its Investigation in Terms of Organizational Variables ${ }^{3}$
}

\author{
Sabahat Bayrak Kok, (Prof. Dr.) \\ Mehtap Sarikaya, (PhD Candidate) \\ Hatice Coban (PhD Candidate) \\ Pamukkale University/Turkey
}

doi: 10.19044/esj.2016.v12n35p16 URL:http://dx.doi.org/10.19044/esj.2016.v12n35p16

\begin{abstract}
Organizational voice described as employees' attitude of expressing their opinions to influence organizational activities reluctantly has three varieties of "acquiescent voice" including acquiescence behaviour relying on submission; "defensive voice" including self-defence behaviour because of a certain fear; and "prosocial voice" behaviour toward others relying on cooperation; and these varieties differentiate according to the motives underneath of organizational voice. In the present study, it was investigated whether organizational voice behaviour and varieties of organizational voice behaviour significant origin of organizational change and development exhibit significant difference according to the demographical variables, or not. To that end, a survey study was conducted on the white-collar employees of the Denizli City companies ranked in the ISO 500 list. In the analysis of data collected from 202 white-collar employees, T-Test and ANOVA methods were employed. As a result of these analyses, it was revealed that organizational voice behaviour varieties displayed by employees were not significantly correlated with any demographical variable statistically.
\end{abstract}

Keywords: Organizational voice, acquiescent voice, defensive voice, prosocial voice

\section{Introduction}

Constructive suggestions and critics of employees are vitally important for organizations striving for maintaining their existence in contemporary difficult and tough competition environment. Thus, as it was

\footnotetext{
${ }^{3}$ This study was generated from master thesis named as Decision Making Processes and Organizational Silence
} 
mentioned by Senge (1990), managers could not claim that they could resolve all problems on their own (Detert and Burris, 2007).

Therefore, they are required to execute business management within team-work based on employees' contribution in terms of opinion and willingness because functions and processes could be ensured organizational voice. Accordingly, opportunity given to employees to express their voices plays significant role in organizational performance, innovation, security and operational development processes; and information timely provided to decision makers would enhance quality and accuracy of decisions made. Thus, along this view, organizational voice has been one of the important subjects gained attention of the relevant literature in the recent period. Within the business management literature, there are two approaches regarding organizational voice: the first one describes it as proactive suggestions of employees necessary for accomplishing change; the second approach describes it as existence of applicable procedures which facilitate participation of employees and enhance justice perception (Sehitoglu, 2010).

\section{Literature Review}

\section{Organizational Voice}

Voice usually involves to higher authorities either inside or outside of the managerial hierarchy. Voice is known as interest articulation when it is used in political systems. And in the theory of organizational behaviour, voice is a key concept as it helps to emphasize the repair of deteriorating conditions and the return to previous levels of performance (Farrell, 1983). In the literature of organizational behaviour, voice is seen as an expression of the desire and choice of individual workers to communicate information and ideas to management for the benefit of the organization (Barry and Wilkinson, 2016).

Voice is defined as "the discretionary or formal expression of ideas, opinions, suggestions, or alternative approaches directed to a specific target inside or outside of the organization with the intent to change an objectionable state of affairs and to improve the current functioning of the organization, group, or individual" (Bashshur and Oc, 2015, p. 1531). Organizational voice is a constructive behaviour for development of organization rather than an argument among employees (Dyne and Lepine, 1998). Organizational voice describes the voluntary expression of people's views to influence organizational actions (Bowen and Blackmon, 2003, p. 1394). Voice is a different concept than intimacy behaviours such as helping; and usually relates with organizational citizenship behaviour and situational performance. Behaviours to establish intimacy conserve and develop relationships. On the other hand, voice behaviour includes an action of challenge and accordingly it could result in deterioration of relationships 
although they were initiated for a constructive purpose. Organizational voice behaviour is differentiated from preventive behaviours such as snitching because snitching aims to hinder ongoing practice rather than being constructive. Organizational voice is also different from organizational opposition because organizational opposition includes reporting problems related with conscientious and moral to the relevant departments. By contrast, organizational voice is expressing opinions about how to enhance current work processes. Another concept that should be distinguished from organizational voice is complaint because complaint behaviour indicates displeasure from the current situation and it is not necessary to draw a suggestion for a change. Voice behaviour is different from the roles of employees, written in their job descriptions because these roles are already the ones expected from employees (LePine and Dyne, 1998).

The model suggested in the study of Albert Hirschman (1970) under title of "Exit, Voice and Loyalty" is the most influential classic theory for dynamics of employee voice concept (Yoon, 2012). Hirschman (1970) is the first social scientist who considered voice as an answer given to dissatisfactions with the job. He considered employees' voice and interrupting their work as an indicator of their loyalty to their job. According to him, employees loyal to their organizations express their dissatisfaction loudly when they face such circumstance; but, the ones disloyal to their organization leave their organization (Brinsfield et al., 2009). Freeman and Medoff (1984) mentioned about positive consequences of creating mechanisms through which employees could spread their voice for both employees and employers. Such mechanisms would sometimes result in integrative and sometimes contradictive environments. Whereas mechanism which allows employees to express their opinions would beneficent organizational results such as increasing quality and productivity, sometimes they would complicate current problems further and transform them into uncontrollable circumstances. In the study of Spencer (1986), conducted on hospital employees, it was concluded that employees who were entitled necessary power to make changes on the issues about which they disrupted are disposed to continue work for their organization; this result supports the suggestion proposed by Hirschman. McCabe and Lewin (1992) claim that voice is consisted of two elements: One of these elements is reporting mechanism for employees about their complaints and worries; the second is participation of employees into decision making processes in the organization. Boroff and Lewin (1997), as result of their research on work places with no any union contract, obtained controversial findings to the views claimed by researchers under leadership of Hirschman. In studies of Boroff and Lewin, employees' raising voice against the unjust practices and policies at the work place and having their words about them is found to be 
positively correlated with their intention of quitting job; and to be negatively correlated with their job commitment. According to the researchers, employees committed to their jobs probably prefer remain silent and endure unjust practices that they encounter or witness at their work place.

Dyne et al. (2003) describe organizational voice as "expression of constructive opinions, ideas and knowledge to develop their organization". They stated that silence includes less behavioural clues in comparison with voice; it is accompanied with more uncertainty for observers; it is difficult to foresee the reasoning behind it; and it may result in more divergent outcomes. Furthermore, they claimed that voice is a proactive behaviour consisted of constructivist suggestions made for change in the name of group or organization of which an individual is its member (Botero and Dyne, 2009).

Table 1. Formal and informal voice mechanisms

Formal voice mechanisms

Grievance processes

One-to-one meetings

Speak-Up programme

Email

Open door policy

Empowerment by supervisor

Self-managed teams

Team briefings

Quality circles

Suggestion schemes

Joint Consultative Committee

Works Councils

Continuous improvement teams

Ombudsman

Mediation

Arbitration

Internal Tribunals

Intranet

Source: Mowbray, Paula K., Adrian Wilkinson, and Herman HM Tse. (2015). "An integrative review of employee voice: identifying a common conceptualization and research agenda." International Journal of Management Reviews, 17/3, p. 389.

Millward et al. (2000) reported three different ways of organizational voice: official participation by means of union membership, consulting mechanisms including indirect participation of employees, similar to the professional expert consultants, and the mechanisms including direct participation of employees (Dundon et al., 2007). Organizations establish systems through which their employees could report their suggestion, opinions, concerns and complaints. Organizational mediatory practices such as open-door policies, request-complaint procedures are considered as voice systems at organizations. As these systems enhance job satisfaction and commitment of employees, syndication , number of filing suits against the 
organization and leave of employment. These systems not only provide employees chance of expressing their opinions before the relevant decisions are taken, but also challenge against these decisions after they are made (Pinder and Harlos, 2001). Mowbray et al. (2015) suggested that developing both formal and informal mechanisms would help organizations to raise to voice and benefit from it. Formal and informal mechanisms that allow companies to raise the voice is shown in Table 1.

Technology Mastery Institute (2014) generated a process to develop organizational voice. This process described as step-by-step:

1. Study potential constituents to establish conversation, determine what preferred methods of communication will be, and articulate the content stream that will be most valuable to them,

2. Choose the appropriate channel(s) to deliver the voice,

3. Choose the right team that will be responsible for managing the voice and providing the content,

4. Decide on the tone of the voice, content mix, and frequency of content delivery,

5. Run a test of the voice with a limited number of readers/listeners,

6. Develop a measurement system for gauging progress,

7. Roll out your organizational voice to the full audience and develop methods for signing up as many people as possible,

8. Never stop refining the content mix, expanding the audience, and interacting with readers/viewers/listeners.

Detert and Burris (2007) describe organizational voice concept as submission of employees' opinions regarding development of organizational operation willingly to the perceived authority. These opinions could challenge against dominate status-quo and authority within the organization. The consequent reaction of organizations against such initiatives is important at this point. If employees think that they are regarded and their suggestions are considered seriously, they express their opinion freely; otherwise, if employees find expressing their opinions more risky than remaining silent, they keep quiet and do not expose their opinions (Detert and Burris, 2007). Especially, in majority of studies conducted afterwards of Van Dyne et al., the attention has focused on supportive and incentive aspects of organizational voice; and on discourses concerning developing current work processes and/or procedures to support the organization.

In comparison, there are only limited researches on the discourse that organization member express their opinions about incidents, practices, behaviours which hinder or tarnishing their organization more (Graham, 1986; Rusbult et. al. 1988, Kowalski, 1996). However, preliminary studies concentrated on the fact that organizational voice prevent or change unfavourable situations in organizations. In order to fulfil this need, Liang et 
al. (2012) investigated organizational voice under two titles: supportive and preventive voice. In their study conducted on 239 employees, no any significant relationship was determined between the individuals' feelings that they have to express their voices and supportive voice. Moreover, no significant relationship was determined between psychological safety feeling and preventive voice. Although obligatory voice of individuals strengthen psychological safety feeling in both voice types, self-confidence behaviour weakens this effect on encouraging voice (Liang et al., 2012).

\section{Organizational Voice Types}

In the present study, organizational voice classification suggested by Dyne et al. (2003) refer organizational voice with three different names based on motives underneath: submissive acquiescence behaviour; selfdefence behaviour subject to fear; and cooperative behaviours toward others. There are three different organizational voice based on these motivations: acquiescent voice, defensive voice and prosocial voice.

\section{Acquiescent Voice}

The first one of them is Abilene Paradox just mentioned; and the second one is pluralist ignorance or pluralist illiteracy. Abilene Paradox (Harvey, 1988) is that expressing individual opinions along the opinion of majority of people so as to maintain conformity. This behaviour neither takes time nor necessitates burden to express their voice. As a second example, plural ignorance considers that an individual thinks that his opinion is the unique opinion within his group; and thus, he expresses his opinions along the opinions of others. In fact, the person at the table does not agree with the ultimate idea but the opinion seems like dominant transformed into a common opinion in a weird way. Thus, group decision relies on assumption and knowledge which deviated from the reality. Pluralist ignorance is also example of acquiescent voice behaviour because individuals make their discourses along the common opinion of the group instead of their personal ideas (Dyne et al., 2003).

Within this behaviour, employees express their opinions but this voice does not represent their personal ideas, opinions and knowledge. This situation could be best expressed with phrases of 'it suits me' (not to spend more time for better alternative), 'whatever you think' (refusing to accept supervising position to resolve the problem) (Sehitoglu, 2010).

\section{Defensive Voice}

The motivation underneath the defensive voice behaviour is fear. Since employees are concerned about consequences, they express their opinion, knowledge and ideas as they are expected to do so in order to 
protect themselves. Defensive voice is a self-protection behaviour. Schlenker and Weigold (1989) characterize self-protection behaviour together with security decisions, taking over less personal supervising responsibility and associate results with external factors (Dyne et al., 2003). One of the important problems at this point is the tendency of employees to voice the expected opinion to encounter less reaction about organizational developments instead of their concerns to protect themselves. Hence, these studies could be an important obstacle before the change. The point necessary to be changed in the organization could turn into a serious problem (Detert and Burris, 2007).

In a study conducted on the subject, it was reported that behaviours such as apology, excuse and denial are the ones displayed against a threat in an organization. Aforesaid behaviours were considered as defensive voice behaviours (Sehitoglu, 2010).

\section{Prosocial Voice}

Prosocial voice behaviour is to protect others. Since prosocial voice prioritizes others, individuals speak up for benefits of others. But in defensive voice, the purpose is to protect oneself. Prosocial voice is type of organizational citizenship behaviour (Durak, 2012).

Prosocial voice means that employees ability to imply issues in an organization which places an emphasis on enhancement of its personnel and rely on trust so that this organization gain better structure (Gao et al., 2011). Prosocial voice is to make explanations about knowledge, feelings and ideas concerning job underneath of cooperation phenomenon. Prosocial voice behaviour is not perceived as positive by everyone (Dyne et al., 2003). Prosocial voice resembles defensive silence with the respect that it requires conscious, proactive and laborious. Since this behaviour is optional, it is difficult to steer by organizations (Sehitoglu, 2010).

\section{Research}

\section{Purpose and Scope of the Research}

Employees are viewed as resources of change, innovation and creativeness which influence organizational performance (Oldham and Cummings, 1996; Youndt et al., 1996; Calantone et al., 2002; Shin et al., 2012). Open-door policies, suggestion and complaint systems, and sharing meetings participated by employees from all departments, which have been developed along recent years and placed in prominence by organizations are the platforms in which employees find opportunity to share their opinion and to speak up. These practices provide opportunities to speak up their voices about issues realized by employees concerning their organizations and jobs, their suggestions or to share their opinions about practices to increase 
productivity and efficiency across the organization. In order to describe such a behaviour, two different examples could be suggested from the management and social psychology literature; "Abilene paradox" and "Being unaware from the mass". Abilene paradox describe situations that people stay in communication with others but do not make any effort or spend any time to add their own thoughts into the communication. Sharing opinions, ideas and interests of employees about a certain subject in an organization is called as organizational voice. Employees could reflect their opinion, feeling, consideration and suggestions concerning their organization by participating into decision making process; in other words, they could voice. The purpose of the present study is to investigate organizational voice types significantly important for organizations and to determine whether organizational voice behaviour differs in terms of demographical variables. In this regard, the relevant hypotheses prepared for this purpose, which will be tested in this research were presented below:

$\mathrm{H}_{1}$ : Organizational voice behaviour exhibits significant difference according to gender.

$\mathrm{H}_{2:}$ Organizational voice behaviour exhibits significant difference according to age.

$\mathrm{H}_{3}$ : Organizational voice behaviour exhibits significant difference according to marital status.

$\mathrm{H}_{4:}$ Organizational voice behaviour exhibits significant difference according to rank.

$\mathrm{H}_{5}$ : Organizational voice behaviour exhibits significant difference according to education level.

$\mathrm{H}_{6 \text { : }}$ Organizational voice behaviour exhibits significant difference according to department.

$\mathrm{H}_{7}$ : Organizational voice behaviour exhibits significant difference according to title.

\section{Research Methodology}

Quantitative research method has been applied in this study. Survey method, which is mostly preferred in social sciences, adopted as a data collection tool in the present study. Organizational voice scale developed by Dyne, Ang and Botero (2003) with 15 expressions regarding the organizational voice from the organizational silence and voice scale were included. Additionally, 7 expressions regarding demographical variables were included.

The universe of the study includes Denizli Companies listed in the Istanbul Chamber of Industry 500 Index. Sampling group is consisted of white collar employees from the Denizli companies in the ISO 500 index published on the corporate website. Parallel to the purpose of the study, it 
was decided to conduct face-to-face survey, one of the primary data collection methods. And simple sampling method had to be used as being a participant depends on volunteerism. Totally 673 white-collar employees were distributed; and ultimately 213 survey form was collected back. However, 11 of these answered surveys were disregarded since they were found unreliable because they were either incomplete or all questions were given the same answer. Resting 202 surveys were included in the analysis. When it is considered that return rate is about 20 to $40 \%$ among applied researches from the saplings selected from the universe (Ogut, 2003), a return rate of $30.1 \%$ that we achieved in this study could be considered as an acceptable rate.

In evaluation of collected data, frequency distributions were analyzed in order to reveal respondents' demographical variables. Furthermore, independent t-test and variance analysis (ANOVA) were applied so as to determine whether organizational voice behaviour display difference with respect respondents’ demographical variables.

\section{Findings}

Reliability analysis results conducted to measure internal consistency of the scale was exhibited in Appendix 1. Reliability level of the 15-item organizational voice scale was determined as $73.3 \%(\alpha=.733)$. In order to admit that a scale is reliable, the minimum acceptable alpha coefficient was required to be minimum 0.7 (Altunışık et al., 2012). Since alpha values for scales utilized in this study and for each dimensions regarding these scales were greater than 0.7 , it was possible to conclude that scales were reliable and appropriate for further analysis.

In order to measure structural validity of scales, factor analysis was conducted. As a result of this analysis, Kaiser-Meyer-Olkin (KMO) test value for the Organizational Voice Scale was estimated at 0.835. If the KMO test value is greater than 0.5, this suggests that data set is appropriate for factor analysis. Barlett's test value $\left(\mathrm{p}=0.000 / \chi^{2}=1515.793 ; \mathrm{p}<0.01\right)$ was found to be significant. As a result of the factor analysis, three factors were determined based on the origin of the scale. The results were exhibited in Appendix 2.

General information on 202 respondent employees regarding their socio-demographical variables was exhibited in Table 2. When gender distribution of respondents is taken into consideration, it was observed that male and female were $32.7 \%$ and $67.3 \%$, respective. In terms of education level, primary education (primary school and secondary school), high school, associate level, bachelor level and graduate levels were distributed as 5\%, $23.3 \%, 21.35 \%, 44.6 \%$ and 5.9\%, respectively. Since the study was conducted on white-collar employees, high education level determined 
among employees were not surprising. According to age distribution of respondents, 29.2\% were in age group of 20-29; $45 \%$ were in group of 30 $39 ; 21.3 \%$ were in age group of $40-49 ; 4 \%$ were in age group of $50-59$; and only 1 person was in age group of 60 and older. It was remarkable that respondents were mostly concentrated around age group of 30-39. In terms of marital status, $70.8 \%$ of respondents were married; and $29.2 \%$ were single. According to the distribution of work period, $5 \%$ of employees had work experience less than a year; 35.6\% had experience 1 to 5 years; 29.7\% were experienced 6 to 10 years; 15.3\% were experienced 11 to 15 years; $11.4 \%$ were experienced 16 to 20 years; and 6\% had experience 20 years and more. According to the departments of employees, $39.6 \%$ were from the manufacturing department; $17.8 \%$ were from the finance department; $7.4 \%$ were from both the sales and marketing and the HR department; $12.9 \%$ were from the engineering and $\mathrm{R} \& \mathrm{D}$ department. $45 \%$ of respondents were clerk or engineer departments.

Table 2. General Characteristics of Respondents

\begin{tabular}{cccccccc} 
& & $\mathbf{N}$ & $\mathbf{\%}$ & & & $\mathbf{N}$ & $\mathbf{\%}$ \\
\hline Gender & Female & 66 & 32.7 & Education & Primary School & 10 & 5.0 \\
& Male & 136 & 67.3 & Level & High School & 47 & 23.3 \\
& & & & Associate & 43 & 21.3 \\
& & & & Bachelor & 90 & 44.6 \\
Age & $20-29$ & 59 & 29.2 & Department & Manufacturing & 80 & 39.6 \\
& $30-39$ & 91 & 45.0 & & Sales and Mar. & 15 & 7.4 \\
& $40-49$ & 43 & 21.3 & & Finance & 36 & 17.8 \\
& $50-59$ & 8 & 4.0 & & HR & 15 & 7.4 \\
& $60 \geq$ & 1 & .5 & & Eng.-R\&D & 26 & 12.9 \\
Marital & Married & 143 & 70.8 & Title & Other & 30 & 14.9 \\
status & Single & 59 & 29.2 & & Clerk/Eng. & 91 & 45.0 \\
& & & & & Sprv./Expert & 47 & 23.3 \\
& & & & & Chief & 30 & 14.9 \\
& & & & & Manager & 20 & 9.9 \\
Work & $1<$ & 10 & 5.0 & & Other & 14 & 6.9 \\
\hline Period & $1-5$ & 72 & 35.6 & & & & \\
& $6-10$ & 60 & 29.7 & 15.3 & & & \\
\end{tabular}

Descriptive analysis results, which indicate mean values of answers given by employees participated in the research to measure organizational voice behaviour of employees, exhibited in Appendix 3. When expressions regarding voice behaviour displayed by the participant employees in their organizations are taken into consideration, it was observed that defensive voice behaviour, displayed because of the fear felt against the consequences of their voice, was "low" ( $\bar{x}=1.78)$; the acquiescent voice behaviour, answers given by individuals who think that their different opinions do not make 
difference, in a way that they conform to others' opinion, was "medium" $(\overline{\mathrm{x}}=3.18)$; the voice behaviour, answered by individuals to protect their organizations and co-workers in dominantly participative way, was "high" $(\overline{\mathrm{x}}=4.16)$ (see: Appendix 3).

In order to test the hypothesis of the study, independent t-test and Anova tests were conducted. Results of these tests were exhibited in following tables:

Table 3. Independent T-Test Results According to Gender

\begin{tabular}{|c|c|c|c|c|}
\hline Dimension & Gender & $\operatorname{MEAN}(\overline{\mathrm{x}})$ & $\begin{array}{c}\text { Standard } \\
\text { Deviation }\end{array}$ & Sig (p) \\
\hline $\begin{array}{c}\text { Organizational } \\
\text { Voice }\end{array}$ & Male & 2.80 & .446 & \multirow{2}{*}{0.57} \\
\cline { 2 - 4 } & Female & 2.95 & .381 & \\
\hline
\end{tabular}

Based on Table 3, according to the independent t-test results, since $\mathrm{p}>0.05$, organizational voice variable does not exhibit significant difference according to gender. Thus, $\mathrm{H}_{1}$ hypothesis was not accepted.

Table 4. Anova Test Results According to Age

\begin{tabular}{|c|c|c|c|c|}
\hline \multirow{2}{*}{ Dimension } & Age Groups & MEAN $(\overline{\mathrm{x}})$ & $\begin{array}{c}\text { Standard } \\
\text { Deviation }\end{array}$ & \multirow{2}{*}{ Sig $(\mathrm{p})$} \\
\hline \multirow{4}{*}{ Organizational Voice } & $20-29$ & 2.99 & .419 & \multirow{3}{*}{.790} \\
\cline { 2 - 4 } & $30-39$ & 3.02 & .348 & \\
\cline { 2 - 4 } & $40-49$ & 3.04 & .403 & \\
\cline { 2 - 4 } & $50-59$ & 3.10 & .170 & \\
\cline { 2 - 4 } & $60 \geq$ & 3.40 & .230 & \\
\hline
\end{tabular}

Since $p>0.05$ in the ANOVA test conducted in order to test whether organizational voice behaviour exhibit difference according to age, it was concluded that organizational voice behaviour does not exhibit difference according to age. Thus, $\mathrm{H}_{2}$ hypothesis was not accepted as well.

Table 5: Independent T-Test Results According to Marital Status

\begin{tabular}{|c|c|c|c|c|}
\hline Dimension & Gender & MEAN $(\overline{\mathrm{x}})$ & $\begin{array}{c}\text { Standard } \\
\text { Deviation }\end{array}$ & Sig (p) \\
\hline \multirow{2}{*}{ Organizational Voice } & Married & 3.03 & .379 & \multirow{2}{*}{.498} \\
\cline { 2 - 4 } & Single & 2.99 & .369 & \\
\hline
\end{tabular}

Based on the Table 5, according to independent t-test results, since $\mathrm{p}>0.05$, organizational voice variable does not exhibit significant difference according to marital status. Thus, $\mathrm{H}_{3}$ hypothesis was not accepted.

Table 6: Anova Test Results According to Rank

\begin{tabular}{|c|c|c|c|c|}
\hline \multirow{2}{*}{ Dimension } & Age Groups & MEAN $(\overline{\mathrm{x}})$ & $\begin{array}{c}\text { Standard } \\
\text { Deviation }\end{array}$ & \multirow{2}{*}{ Sig (p) } \\
\hline \multirow{4}{*}{$\begin{array}{c}\text { Organizational } \\
\text { Voice }\end{array}$} & $1 \leq$ & 2.97 & .151 & \multirow{3}{*}{.488} \\
\cline { 2 - 4 } & $1-5$ & 3.04 & .413 & \\
\cline { 2 - 4 } & $6-10$ & 2.96 & .374 & .327 \\
\cline { 2 - 4 } & $11-15$ & 3.05 & .421 & \\
\cline { 2 - 4 } & $16-20$ & 3.14 & .355 & \\
\cline { 2 - 4 } & $21 \geq$ & 3.40 & \multicolumn{2}{|c|}{} \\
\hline
\end{tabular}


Based on the variance analysis results in Table 6 , since $p>0.05$, organizational voice variable does not exhibit significant difference according to rank. Thus, $\mathrm{H}_{4}$ hypothesis was not accepted.

Table 7. Anova Test Results According to Education Level

\begin{tabular}{|c|c|c|c|c|}
\hline \multirow{2}{*}{ Dimension } & Age Groups & MEAN $(\overline{\mathrm{x}})$ & $\begin{array}{c}\text { Standard } \\
\text { Deviation }\end{array}$ & \multirow{2}{*}{ Sig (p) } \\
\hline \multirow{4}{*}{$\begin{array}{c}\text { Organizational } \\
\text { Voice }\end{array}$} & Secondary & 3.28 & .363 & \\
\cline { 2 - 4 } & High School & 2.94 & .348 & \multirow{3}{*}{.100} \\
\cline { 2 - 4 } & Associate & 3.03 & .416 & \\
\cline { 2 - 4 } & Bachelor & 3.02 & .358 & \\
\cline { 2 - 4 } & Graduate & 3.12 & .405 & \\
\hline
\end{tabular}

Since $\mathrm{p}>0.05$ in the ANOVA test conducted to determine whether organizational voice behaviour differs according to age, organizational voice behaviour does not exhibit difference according to education status. Thus, $\mathrm{H}_{5}$ hypothesis was not accepted.

Table 8: Anova Test Results According to Department

\begin{tabular}{|c|c|c|c|c|}
\hline \multirow{2}{*}{ Dimension } & Age Groups & MEAN $(\overline{\mathrm{x}})$ & $\begin{array}{c}\text { Standard } \\
\text { Deviation }\end{array}$ & \multirow{2}{*}{ Sig (p) } \\
\hline \multirow{4}{*}{$\begin{array}{c}\text { Organizational } \\
\text { Voice }\end{array}$} & Manufacturing & 3.00 & .330 & \multirow{2}{*}{.323} \\
\cline { 2 - 4 } & $\begin{array}{c}\text { Sales and } \\
\text { Marketing }\end{array}$ & 3.11 & .382 & \multirow{2}{*}{.905} \\
\cline { 2 - 4 } & Finance & 3.00 & .407 & \\
\cline { 2 - 4 } & Human Resources & 3.08 & .486 & \\
\cline { 2 - 4 } & $\begin{array}{c}\text { Engineering, } \\
\text { R\&D }\end{array}$ & 3.00 & .330 & \\
\cline { 2 - 4 } & Other & 3.00 & \\
\hline
\end{tabular}

Based on the variance analysis results in Table 8 , since $\mathrm{p}>0.05$, organizational voice variable does not exhibit significant difference according to respondents' job departments. Thus, $\mathrm{H}_{6}$ hypothesis was not accepted.

Table 9. Anova Test Results According to Title

\begin{tabular}{|c|c|c|c|c|}
\hline \multirow{2}{*}{ Dimension } & Age Groups & MEAN $(\overline{\mathrm{x}})$ & $\begin{array}{c}\text { Standard } \\
\text { Deviation }\end{array}$ & \multirow{2}{*}{ Sig (p) } \\
\hline \multirow{4}{*}{$\begin{array}{c}\text { Organizational } \\
\text { Voice }\end{array}$} & Clerk, Engineer & 2.99 & .389 & \multirow{2}{*}{} \\
\cline { 2 - 4 } & $\begin{array}{c}\text { Supervisor, } \\
\text { Expert }\end{array}$ & 3.05 & .429 & \multirow{2}{*}{.675} \\
\cline { 2 - 4 } & Chief & 3.09 & .241 & \\
\cline { 2 - 4 } & Manager & 2.98 & .217 & \\
\cline { 2 - 4 } & Other & 3.05 & .509 & \\
\hline
\end{tabular}

Since $\mathrm{p}>0.05$ in the ANOVA test conducted to determine whether organizational voice behaviour differs according to title, it was determined that organizational voice behaviour does not differ significantly according to job title and position. Thus, $\mathrm{H}_{7}$ hypothesis was not accepted. 


\section{Conclusion}

Expression of constructivist opinions, ideas and knowledge of employees to develop their organization are referred as organizational voice. When the research findings are taken into consideration, "medium level" voice behavior could be observed among employees of the companies in the sampling group.

The first dimension of the organizational voice is "acquiescent voice" which means expressing opinion in a way conforming to others' opinion because of the hesitation that personal opinion would not make any ultimate difference. The second dimension is "defensive voice" which is described as expressing the opinion which is believed to encounter less reaction because employees are scared the relevant consequences. The third dimension is "prosocial voice" structured on cooperation, described as knowledge, opinion and ideas about the job. When voice dimension was considered, it was remarkable that it was determined as "low level", "medium level" and "high level" with defensive voice dimension, acquiesced voice dimension, and prosocial voice dimension, respectively; and no significant difference was determined between organizational voice and demographical factors. In sum, according to research results, organizational voice does not exhibit difference according to employees' gender, age, education level, marital status, rank, job department and job titles. All hypotheses of the research were rejected. Organizational voice is priority of managers for ensuring all operations.

\section{Limitations and Future Improvements}

Considering that the results of the study may be affected by some limitations, it is necessary to express these situations. First of all, the study was conducted just at city limits. When we consider the cultural effects, we can understand the reason of similarities. This may be the reason for the rejection of all hypotheses. Secondly, the study was just conducted in companies which took part in ISO 500 list means all of them were already big and successful companies. I think that they may have such organizational culture in which there is not any difference according to peoples' gender, age, department or any other variables when considering peoples' ideas and opinions. Another limitation is that the number of samples in the study is not so high. Last but not least, random sampling method should be used in the studies which aim to analyze organizational variables to measure if there is any difference between them. However, because of forcing the participation would not be appropriate, we used simple sampling as most of researchers did.

According to the research results, there are two kinds of suggestions. First one is about managers and for their companies, and the second one is 
for the further studies. Employees organizational voice level is medium as seen in Appendix 3. This means that they often avoid expressing their ideas. That's why, managers are required to listen to employees who express issues and concerns which they encounter sincerely; to be supportive; and to create a work environment in which employees feel safe. As manager-leaders, they are required to display more participative and democratic attitude. By encouraging organizational voice in practices, they need to reduce organizational silence. In this regard, open-door policies are required to be adopted; employee boards are to be structured; various methods such as brain storming, nominal group, multiple-voting and Delphi in decision making process and problem solving; and their practices are required to be increased and extended. Suggestions for the further studies is mostly related with the limitations of this study. Future studies should be conducted in more than one city, at different levels of companies and with more participants because of the reasons explained above.

\section{References}

1. Altunışık, Remzi, Recai Coşkun, Serkan Bayraktaroglu and Engin Yıldırım (2012). Sosyal Bilimlerde Araştırma Yöntemleri, Sakarya Bookstore, Seventh Edition, Sakarya.

2. Barry, Michael, and Adrian J. Wilkinson (2016). "Pro-social or pro-management? A critique of the conception of employee voice as a pro-social behaviour within organizational behaviour." British Journal of Industrial Relations, 54/2, pp. 261284.

3. Bashshur, Michael R., and Burak Oc. (2015). "When voice matters A multilevel review of the impact of voice in organizations." Journal of Management 41/5, pp. 1530-1554.

4. Botero, Isabel C. and Linn Van Dyne (2009). "Employee Voice Behaviour Interactive Effects of LMX and Power Distance in the United States and Colombia." Management Communication Quarterly, 23/1, pp.84-104.

5. Bowen Frances and Blackmon Kate (2003). " Spirals of Silence: The Dynamic Effects of Diversity on Organizational Voice", Journal of Management Studies, 40/6, pp. 1393-1417.

6. Brinsfield, Chad T., Marissa S. Edwards and Jerald Greenberg (2009). Voice and Silence in Organizations: Historical Review and Current Conceptualizations. J. Greenberg and M. Edwards. In Voice and Silence in Organizations, 3-31, UK, Emerald Group Publishing Limited. 
7. Calantone, R. J., Cavusgil, S. T., and Zhao, Y. (2002). "Learning Orientation, Firm İnnovation Capability, And Firm Performance”, Industrial Marketing Management, 31/6, pp. 515-524.

8. Detert, James R and Ethan R. Burris (2007). "Leadership Behaviour and Employee Silence: Is the Door Really Open?”, The Academy of Management Journal, 50/4, pp.869-884.

9. Dundon, Tony (2004). "The Meanings and Purpose of Employee Voice”, International Journal of Human Resource Management, 15/6, pp.1149-1170.

10. Durak, İbrahim (2012). Korku Kültürü ve Örgütsel Sessizlik, Ekin Press, First Edition, Bursa.

11. Dyne, Linn Van and Jeffrey A. Lepine (1998). "Helping and Voice Extra-Role Behaviour: Evidence of Construct and Predictive Validity", The Academy of Management Journal, 41/1, pp.108-119.

12. Dyne, Linn Van, Jill W. Graham and Richard M. Dienesch (1994). "Organizational Citizenship Behaviour: Construct Redefinition, Measurement, and Validation", The Academy of Management Journal, 37/4, pp.765-802.

13. Farrell Dan (1983). "Exit, Voice, Loyalty, and Neglect as Responses to Job Dissatisfaction: A Multidimensional Scaling Study", The Academy of Management Journal , 26/4, pp. 596-607.

14. Gao, L., Janssen, O. and Shi, K. (2011). "Leader trust and employee voice: The moderating role of empowering leader behaviours." The Leadership Quarterly, 22/4, pp. 787-798.

15. Graham, J. (1986) Principled organizational dissent: A theo retical essay. In B. M. Staw \& L. L. Cummings (Eds.), Re search in organization behavior (Vol. 8, pp. 1-52). Green wich, CT: JAI Pres.

16. Harvey, Jerry B. (1988) "The Abilene Paradox: The Management of Agreement." Organizational Dynamics, 17/1, pp. 17-43.

17. Kowalski, R. M. (1996). "Complaints and Complaining: Functions, Antecedents, and Consequences”. Psychological Bulletin, 119/2, pp. 179-196.

18. LePine, Jeffrey A. and Linn Van Dyne (1998). "Predicting Voice Behaviour in Work Groups." Journal of Applied Psychology, 83, pp.853-868.

19. Liang, Jian, Crystal IC Farh and Jiing-Lih Farh (2012). "Psychological Antecedents Of Promotive and Prohibitive Voice: A Two-Wave Examination." Academy of Management Journal, 55/1, pp.71-92.

20. Mowbray, Paula K., Adrian Wilkinson, and Herman HM Tse. (2015). "An integrative review of employee voice: identifying a common 
conceptualization and research agenda." International Journal of Management Reviews, 17/3, pp. 382-400.

21. Ogut, Adem (2003). "Küçük ve Orta Ölçekli Sanayi İşletmelerinde Kriz Yönetimi Yaklaşımları: Tekstil Sektörü Örneği”, Selcuk University Journal of Social Sciences Institute, 9, pp. 287-304.

22. Oldham, G. R. and Cummings, A. (1996). "Employee Creativity: Personal and Contextual Factors at Work. Academy of Management Journal, 39/3, pp. 607-634.

23. Pinder, C. C. and Harlos, K. P. (2001). "Employee Silence: Quiescence and Acquiescence as Responses to Perceived Injustice", Research in Personnel and Human Research Management, 20, pp.331-369.

24. Rusbult CE, Farrell D, Rogers G and Mainous AG. (1988). "Impact of Exchange Variables on Exit, Voice, Loyalty, And Neglect: An Integrative Model of Responses to Declining Job Satisfaction". Academy of Managament Journal, 31, pp. 599-627.

25. Sehitoglu, Yasin (2010). Relationship between Organizational Silence and Organizational Citizenship Behaviour and Perceived Performance, (Unpublished Doctoral Dissertation), Gebze High Technology Institute, Social Sciences Institute, Kocaeli.

26. Shin, J., Taylor, M. S., and Seo, M. G. (2012). "Resources For Change: The Relationships Of Organizational Inducements and Psychological Resilience to Employees' Attitudes and Behaviors Toward Organizational Change" Academy of Management Journal, 55/3, pp. 727-748.

27. Spencer, Daniel G. (1986). Employee Voice and Employee Retention, The Academy of Management Journal, 29/3, pp. 488-502.

28. Technology Mastery Institute (2014). "Process to Develop Organizational Voice", http://www.fpov.com/wpcontent/uploads/2014/06/Organizational-Voice-Process.pdf (Last Accessed: 18/11/2016).

29. Yoon, Hea Jun (2012). Predicting Employee Voice Behaviour: An Exploration of the Roles of Empowering Leadership, Power Distance, Organizational Learning Capability, and Sense of Empowerment in Korean Organizations, (Unpublished Doctoral Dissertation), Minnesota University, USA.

30. Youndt, M. A., Snell, S. A., Dean, J. W., and Lepak, D. P. (1996). "Human Resource Management, Manufacturing Strategy, and Firm Performance” Academy of Management Journal, 39/4, pp. 836-866. 


\section{Appendices:}

Appendix 1. Reliability Analysis Results

\begin{tabular}{|c|c|c|}
\hline Dimensions & Number of Expression & Cronbach's Alpha $(\alpha)$ \\
\hline Organizational Voice & 15 & .733 \\
\hline a. Acquiescent Voice & 5 & .714 \\
\hline b. Defensive Voice & 5 & .885 \\
\hline c. Prosocial Voice & 5 & .813 \\
\hline
\end{tabular}

Appendix 2. Eigenvalue and Variances of Organizational Voice Scale Factors

\begin{tabular}{|c|c|c|c|}
\hline Factor No & Eigenvalue & Variance & Cumulative \\
\hline 1 & 4.945 & 27.616 & 27.616 \\
\hline 2 & 2.769 & 22.506 & 50.123 \\
\hline 3 & 1.420 & 10.770 & 60.892 \\
\hline
\end{tabular}

KMO test value: $\mathbf{0 . 8 3 5}$

Bartlett test sig. value: .000

$\chi^{2}=1515.793$

Appendix 3. Mean and Standard Deviation Values Regarding Organizational Voice Scale

\begin{tabular}{|c|c|c|c|}
\hline Organizational Voice & $\begin{array}{c}\text { Mean } \\
\overline{\mathrm{x}}\end{array}$ & $\begin{array}{l}\text { Standard } \\
\text { Deviation }\end{array}$ & Level* \\
\hline Acquiescent Voice & 3.18 & 1.052 & MEDIUM \\
\hline $\begin{array}{l}\text { I participate in group decisions because I think that my } \\
\text { suggestions will not make any difference in group } \\
\text { decisions. }\end{array}$ & 3.93 & .855 & High \\
\hline I adjust to opinions of others in resolution of issues. & 3.69 & 1.057 & High \\
\hline I prefer to support suggestions of my co-workers. & 3.29 & 1.069 & Medium \\
\hline $\begin{array}{l}\text { Since I consider myself insufficient on making } \\
\text { suggestions, I support opinions of my co-workers. }\end{array}$ & 2.68 & 1.119 & Medium \\
\hline $\begin{array}{l}\text { Although I comply with decisions taken, sometime I } \\
\text { express my new opinions }\end{array}$ & 2.31 & 1.161 & Low \\
\hline Defensive Voice & 1.78 & 0.824 & LOW \\
\hline $\begin{array}{l}\text { Since I was frightened (punishment, layoff, preventing } \\
\text { potential promotion etc.), I adopt group decisions. }\end{array}$ & 1.91 & .945 & Low \\
\hline In order to protect myself, I steer discussion to others. & 1.89 & .888 & Low \\
\hline $\begin{array}{l}\text { Because I am hesitating about their consequences, I } \\
\text { support the decisions accepted by my co-workers. }\end{array}$ & 1.85 & .862 & Low \\
\hline $\begin{array}{l}\text { Because I am hesitating about their consequences, I } \\
\text { suggest opinions to distract the attention on myself. }\end{array}$ & 1.71 & .742 & Low \\
\hline $\begin{array}{l}\text { In order to protect myself, I agree with my co- } \\
\text { workers. }\end{array}$ & 1.58 & .687 & Low \\
\hline Prosocial Voice & 4.16 & 0.852 & HIGH \\
\hline
\end{tabular}


I propose opinions for changes beneficent at my work place.

4.27

By observing interest of my work place, I propose solution for problems within cooperative framework.

I make suggestions about the subjects effective on my work place.

I clearly share my opinions about the projects that could be interest of my work place.

Even though other co-workers do not agree, I expose my opinions about my work.

GENERAL MEAN
4.15

4.14

4.13

.858

High

4.12

.894

High

3.04
0.909

MEDIUM

$* \overline{\mathrm{x}}=1-2.59$; Low $\quad \overline{\mathrm{x}}=2.60-3.39$; Medium $\quad \overline{\mathrm{x}}=3.40-5$; High 